\title{
Analisis Minimalisasi Biaya (Cost-Minimization Analysis) Pasien Gastritis Rawat Inap di RSUD Abdul Wahab Sjahranie Samarinda
}

\author{
Muhammad Akbar*, Mirhansyah Ardana, Hadi Kuncoro \\ Laboratorium Penelitian dan Pengembangan Kefarmasian "Farmaka Tropis", \\ Fakultas Farmasi, Universitas Mulawarman, Samarinda, Indonesia \\ *Email: akbarmuhammad0117@gmail.com
}

\begin{abstract}
The cost of health services, especially drug costs, has increased in several last years, one of them is the gastritis drug. The incidence of gastritis in Indonesia is about 40, 8\%, and the incidence of gastritis in some regions in Indonesia is high enough with the prevalence are 274,396 cases from 238,452,952 people. Many people need more economical and efficient medicines, so this analysis is made, namely Pharmacoeconomic Analysis that describes and analyzes the cost of drugs for the health care system. One of them is CMA (Cost-Minimization Analysis) where this method is used to find out or compare two or more therapies that have the minimal cost and have economic value. This research uses descriptive research method with retrospective data collection. The sample in this research consists of 15 cases in period 2017. The most commonly used gastritis drugs in RSUD Abdul Wahab Sjahranie are ranitidine and pantoprazole where 5 cases used ranitidine and 10 cases using pantoprazole. The results show that Ranitidine drug has the minimal cost of Rp.5.200.079, - than of Pantoprazole of Rp. 14.256.345,-.
\end{abstract}

Keywords: Cost Minimization Analysis, Gastritis, Pharmacoeconomics

\begin{abstract}
ABSTRAK
Biaya pelayanan kesehatan, khususnya biaya obat, telah meningkat beberapa tahun terakhir, salah satunya adalah obat gastritis. Tingkat kejadian penyakit gastritis di Indonesia adalah 40, 8\%, dan angka kejadian gastritis di beberapa daerah di Indonesia cukup tinggi dengan prevalensi 274.396 kasus dari 238.452.952 jiwa penduduk. Banyak masyarakat membutuhkan obat-obat yang lebih ekonomis dan efisien, sehingga dibuat suatu analisis yaitu analisis farmakoekonomi yang menggambarkan dan menganalisa biaya obat untuk sistem perawatan kesehatan. Salah satunya adalah CMA (Cost-Minimization Analysis) dimana metode ini digunakan untuk mengetahui atau membandingkan dua atau lebih terapi yang memiliki biaya paling minimal dan memiliki nilai ekonomis. Penelitian ini menggunakan metode penelitian deskriptif dengan pengambilan data secara retrospektif. Sampel pada penelitian ini terdapat 15 kasus pada periode 2017. Obat gastritis yang paling sering digunakan di RSUD Abdul Wahab Sjahranie yaitu ranitidine dan pantoprazol dimana 5 kasus yang menggunakan terapi ranitidine dan 10 kasus yang menggunakan terapi pantoprazole. Hasil penelitian menunjukkan obat Ranitidin memiliki
\end{abstract}


biaya paling minimal yaitu sebesar Rp.5.200.079,- dibandingkan dengan Pantoprazol sebesar Rp.14.256.345,--

Kata Kunci: Analisis Minimalisasi Biaya, Gastritis, Farmakoekonomi

DOI: https://doi.org/10.25026/mpc.v7i1.285

\section{PENDAHULUAN}

Gastritis merupakan penyakit saluran pencernaan yang paling sering ditemukan. Definisi gastritis sendiri adalah suatu kondisi dimana terjadinya peradangan atau inflamasi pada dinding (mukosa) lambung yang disebabkan karena factor iritan dan infeksi bakteri, orang yang menderita gastritis akan mengalami nyeri ulu hati. Gastritis juga dapat terjadi karena meningkatnya produksi asam lambung yang biasanya disebabkan karena pengaruh dari luar atau karena telat makan ${ }^{[1]}$.

Gastritis terbagi menjadi 2 yaitu gastritis akut dan kronik. Gastritis akut masih dapat sembuh dengan cepat tetapi apabila tidak segera ditangani lama kelamaan akan menjadi kronik. Perlu dilakukan penanganan lebih dan tepat apabila telah terjadi gastritis kronik karena akan menimbulkan komplikasi seperti kanker lambung dan peptic ulcer. Dan juga bisa menyebabkan kematian apabila dibiarkan terus-menerus. Tingkat kejadian penyakit gastritis di Indonesia menurut WHO adalah 40, 8\%, dan angka kejadian gastritis di beberapa daerah di Indonesia cukup tinggi dengan prevalensi 274.396 kasus dari 238.452.952 jiwa penduduk $^{[2]}$.

Obat-obat yang sering digunakan untuk mengobati penyakit gastritis yaitu antasida, analog prostaglandin, protonpump inhibitor, antagonis reseptor $\mathrm{H} 2$, sukralfat, koloid bismuth, dan apabila terjadi infeksi bakteri $H$. Pylori maka perlu dilakukan eradikasi H.Pylori. Umumnya obat yang sering digunakan untuk penyakit gastritis yaitu obat golongan proton-pump inhibitor contohnya omeprazole dan pantoprazole serta antasida dan ranitidine. Obat golongan proton-pump inhibitor ini memiliki efek yang lebih kuat dibandingkan dengan obat gastritis lain seperti antasida dan Antagonis $\mathrm{H} 2$ tetapi tidak secara langsung dapat dikatakan bahwa obat golongan proton-pump inhibitor bersifat paling baik dan efektif dalam mengobati gastritis. Obat golongan proton-pump inhibitor digunakan jika gastritis telah kronis atau memiliki tingkat keparahan sedang-berat, sedangkan untuk penyakit gastritis ringan masih dapat digunakan obat antasida atau Antagonis $\mathrm{H}_{2}{ }^{[3]}$.

Berdasarkan penelitian Febryanti Laumba tahun 2017 di RSU Pancaran Kasih GMIM Manado menunjukan bahwa jenis kelamin perempuan $71,43 \%$ lebih banyak menderita gastritis dibandingkan laki-laki 28,57\%. Berdasarkan survey yang dilakukan oleh Febryanti Lumba, obat yang paling banyak digunakan untuk pasien gastritis kronik di RSU Pancaran Kasih GMIM Manado yaitu omeprazole dan pantoprazole. Pada penelitian tersebut bertujuan untuk menentukan obat mana yang memiliki biaya paling minimal. Dimana rata-rata biaya yang dikeluarkan pasien untuk obat omeprazole yaitu Rp. 4.289.296 dan untuk pantoprazole yaitu Rp. 2.467.194. Maka pada penelitian tersebut obat yang paling minimal biayanya adalah pantoprazole.

Oleh karena itu, perlu dilakukan studi farmakoekonomi untuk mengetahui biaya obat yang lebih efisien dan 
ekonomis bagi masyarakat. Efisiensi ekonomi kesehatan dilakukan dengan tujuan agar sumber daya yang tersedia dapat digunakan untuk meningkatkan dan menjamin kesehatan masyarakat seoptimal mungkin. Efisiensi juga berhubungan dengan biaya satuan sumber daya yang digunakan dan hasilnya, dengan demikian terlihat adanya maksimalisasi luaran dan pemilihan alternatif proses pelayanan kesehatan yang terbaik ${ }^{[4]}$.

\section{METODOLOGI PENELITIAN}

Penelitian ini merupakan penelitian observational, data yang diambil meliputi data rekam medik pasien gastritis rawat inap, serta daftar biaya terapi yang berasal dari bagian keuangan di RSUD Abdul Wahab Sjahranie Samarinda.

\section{Jenis Penelitian}

Penelitian ini menggunakan rancangan studi kuantitatif dan pengumpulan data secara retrospektif dengan penjabaran data secara deskriptif dan tabulasi.

\section{Populasi dan Sampel}

Populasi penelitian adalah semua pasien rawat inap penderita penyakit gastritis kronik yang berada di RSUD Abdul Wahab Sjahranie Samarinda periode 2017. Sampel penelitian adalah rekam medik pasien gastritis rawat inap di RSUD Abdul Wahab Sjahranie Samarinda periode 2017. Teknik pengambilan sampel yang digunakan yaitu total sampling.

\section{Teknik Pengumpulan Data}

Penelitiaan ini dilakukan dengan pengambilan data secara Retrospektif. Pengumpulan data dilakukan dengan melihat rekam medik, serta mencatat beberapa parameter yaitu nama, jenis kelamin, usia, pekerjaan, nama obat, frekuensi pemberiaan obat, dosis obat, jenis tindakan yang dilakukan, biaya medic yang dikeluarkan pasien meliputi harga obat, biaya tindakan/laboratorium, biaya rawat inap/ruangan rawat inap, biaya jasa pelayanan dan biaya bahan habis pakai.

\section{Analisis Data}

Analisis yang digunakan yaitu Cost Minimalization Anaysis (CMA). CMA merupakan analisis farmakoekonomi yang dilakukan dengan membandingkan dua atau lebih pilihan terapi untuk menentukan biaya terapi yang paling minimal dan ekonomis bagi pasien dengan menjumlahkan seluruh biaya yang dikeluarkan pasien. Dan untuk menentukan biaya paling minimal per pasien menggunakan rumus:

$$
\text { CMA Per Pasien }=\frac{\text { Total Biaya Medik }}{\text { Jumlah Pasien }}
$$

\section{HASIL DAN PEMBAHASAN}

\section{Karakteristik Subjek Penelitian}

Hasil penelusuran data dari bagian rekam medik di RSUD Abdul Wahab Sjahranie Samarinda diperoleh sebanyak 15 kasus gastritis pada periode 2017. Berdasarkan Tabel 1, jumlah pasien perempuan yang menderita gastritis lebih banyak dibandingkan dengan laki-laki dengan persentase perempuan yaitu $86,67 \%$ dan persentase laki-laki yaitu $13,33 \%$.

Penyakit gastritis sering terjadi pada perempuan karena tingkat stres pada perempuan lebih tinggi dari pada laki laki, dan pada perempuan lebih sulit untuk mengontrol dan mengendalikan emosi yang merupakan pemicu timbulnya stress yang merupakan salah satu faktor penyebab gastritis ${ }^{[5]}$. Stres yang dialami akan berefek pada saluran pencernaan antara lain menyebabkan luka (ulcer) pada saluran pencernaan termasuk lambung. Mekanisme terjadinya luka lambung akibat stres adalah melalui peningkatan asam lambung, yang mengiritasi dinding mukosa lambung dan 
berkurangnya produksi mukus yang berfungsi sebagai lapisan pelindung dinding lambung Hormon juga merupakan salah satu faktor yang mempengaruhi sensitifitas seseorang terhadap nyeri. Perempuan secara biologis lebih sensitif terhadap nyeri daripada laki laki. Hormon wanita lebih reaktif daripada laki-laki. Hal ini sesuai dengan teori yang menyatakan bahwa sekresi lambung diatur oleh mekanisme saraf dan hormonal. Pengaturan hormonal berlangsung melalui hormon gastrin. Hormon ini bekerja pada kelenjar gastrik dan menyebabkan aliran tambahan getah lambung yang sangat asam ${ }^{[6]}$.

Tabel 1. Karakteristik pasien gastritis berdasarkan jenis kelamin di RSUD Abdul Wahab Sjahranie Samarinda

\begin{tabular}{ccc}
\hline Jenis Kelamin & Jumlah & $\%$ \\
\hline Laki-Laki & 2 & $13,33 \%$ \\
Perempuan & 13 & $86,67 \%$ \\
\hline Total & 15 & $100 \%$
\end{tabular}

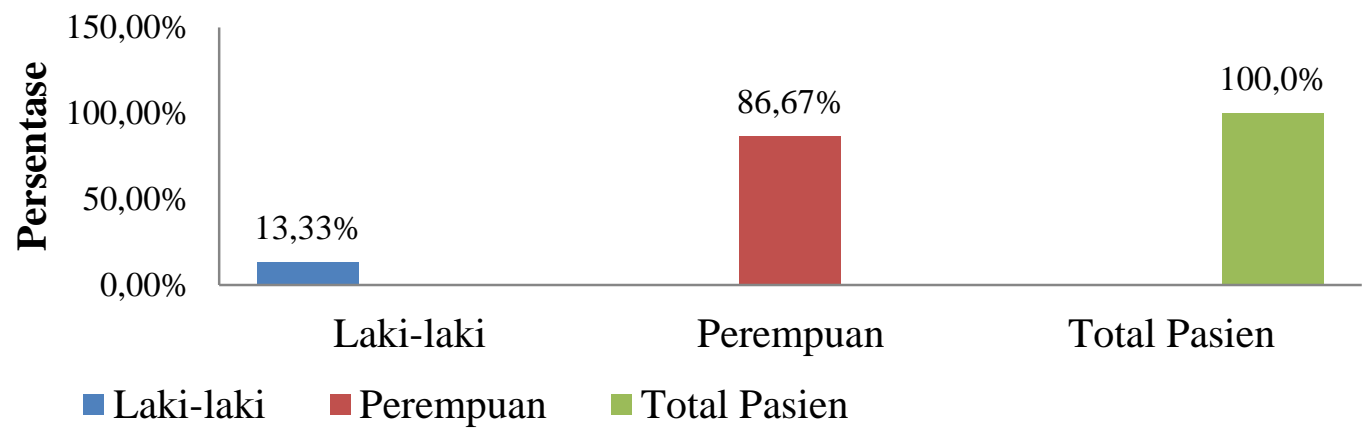

Gambar 1. Diagram Karakteristik pasien gastritis berdasarkan jenis kelamin di RSUD Abdul Wahab Sjahranie Samarinda

\section{Obat Gastritis yang Diberikan Kepada Subjek Penelitian}

Diketahui hasil penelusuran data menunjukkan terdapat 2 obat teratas yang paling sering digunakan di RSUD Abdul Wahab Sjahranie Samarinda yaitu Ranitidin dan Pantoprazol. Berdasarkan Tabel 2, menunjukkan bahwa pengguna pantoprazol lebih banyak dibandingkan dengan ranitidin dengan persentase pantoprazol yaitu $66,67 \%$, sedangkan persentase ranitidin yaitu 33,33\%.

Ranitidin merupakan golongan antagonis reseptor $\mathrm{H} 2$, dimana obat-obat ini menempati reseptor histamin $\mathrm{H} 2$ secara selektif di permukaan sel-sel parietal sehingga sekresi asam lambung dan pepsin sangat dikurangi, sedangkan Pantoprazole bekerja menghambat dengan praktis sekresi asam dengan jalan menghambat enzim $\mathrm{H}+/ \mathrm{K}+-\mathrm{ATPa} e$ secara selektif dalam sel-sel parietal dan menekan sekresi ion hidrogen ke dalam lumen lambung. Sedangkan sucralfat bekerja menetralkan asam dan menahan kerja pepsin ${ }^{[7]}$. 
Tabel 2. Obat gastritis yang paling sering digunakan di RSUD Abdul Wahab Sjahranie Samarinda

\begin{tabular}{ccc}
\hline Nama obat & Jumlah Pasien & $\%$ \\
\hline Ranitidin & 5 & $33.33 \%$ \\
Pantoprazol & 10 & $66.67 \%$ \\
\hline Total & 15 & $100.00 \%$ \\
\hline
\end{tabular}

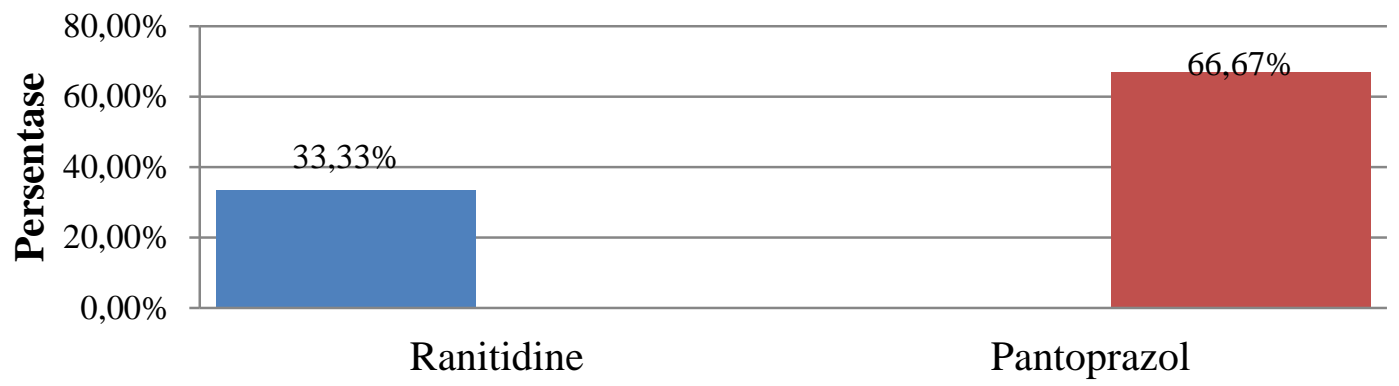

Gambar 2. Diagram Obat gastritis yang paling sering digunakan di RSUD Abdul Wahab Sjahranie Samarinda

Tabel 3. Rincian Data Penggunaan Obat Ranitidine Pada Pasien Gastritis di RSUD Abdul Wahab Sjahranie Samarinda

\begin{tabular}{|c|c|c|c|c|}
\hline No. & $\begin{array}{c}\text { Jenis } \\
\text { Kelamin }\end{array}$ & $\begin{array}{l}\text { Umur } \\
\text { (tahun) }\end{array}$ & Nama Obat & $\begin{array}{c}\text { Lama perawatan } \\
\text { (hari) }\end{array}$ \\
\hline 1 & $\mathrm{P}$ & 29 & $\begin{array}{c}\text { Ranitidine } \\
\text { Inpepsa } \\
\text { Metoklopramid } \\
\text { Omeprazol } \\
\text { KA-EN 3 B Infus }\end{array}$ & 1 hari \\
\hline 2. & $\mathrm{P}$ & 53 & $\begin{array}{c}\text { Ranitidine } \\
\text { Omeprazole } \\
\text { Sukralfat } \\
\text { Domperidone } \\
\text { Cefixime } \\
\text { Ringer Laktat Infus }\end{array}$ & 6 hari \\
\hline 3. & $\mathrm{P}$ & 63 & $\begin{array}{c}\text { Ranitidine } \\
\text { Ondancetron } \\
\text { Ringer Laktat Infus }\end{array}$ & 2 hari \\
\hline 4. & $\mathrm{~L}$ & 7 & $\begin{array}{c}\text { Ranitidine } \\
\text { Ceftriaxone } \\
\text { Dextrose 5\% Infus }\end{array}$ & 4 hari \\
\hline 5. & $\mathrm{P}$ & 27 & $\begin{array}{l}\text { Ranitidine } \\
\text { Omeprazole } \\
\text { Sukralfat } \\
\text { Metoklopramid }\end{array}$ & 1 hari \\
\hline
\end{tabular}


Analisis Minimalisasi Biaya (Cost-Minimization Analysis) Pasien Gastritis Rawat Inap di RSUD Abdul Wahab Sjahranie Samarinda

Tabel 4. Rincian Data Penggunaan Obat Pantoprazol Pada Pasien Gastritis di RSUD Abdul Wahab Sjahranie Samarinda

\begin{tabular}{|c|c|c|c|c|}
\hline No. & Jenis Kelamin & $\begin{array}{l}\text { Umur } \\
\text { (tahun) }\end{array}$ & Nama Obat & $\begin{array}{c}\text { Lama perawatan } \\
\text { (hari) }\end{array}$ \\
\hline 1 & $\mathrm{P}$ & 78 & $\begin{array}{c}\text { Pantoprazol } \\
\text { Braxidin } \\
\text { Rebamipide } \\
\text { Ondancetron } \\
\text { Ringer Laktat Infus }\end{array}$ & 6 hari \\
\hline 2. & $\mathrm{~L}$ & 41 & $\begin{array}{c}\text { Pantoprazol } \\
\text { Metoklopramid } \\
\text { Ceftriaxone } \\
\text { Ringer Laktat Infus }\end{array}$ & 4 hari \\
\hline 3. & $\mathrm{P}$ & 84 & $\begin{array}{c}\text { Pantoprazol } \\
\text { Primperan } \\
\text { Omeprazol } \\
\text { Rabeprazol } \\
\text { KA-EN } 3 \text { B Infus } \\
\end{array}$ & 4 hari \\
\hline 4. & $\mathrm{P}$ & 45 & $\begin{array}{c}\text { Pantoprazol } \\
\text { Fucoidan } \\
\text { Fentanyl } \\
\text { Ringer Laktat Infus }\end{array}$ & 2 hari \\
\hline 5. & $\mathrm{P}$ & 33 & $\begin{array}{l}\text { Pantoprazol } \\
\text { Ondancetron } \\
\text { Na Metamizole } \\
\text { Rebamipide } \\
\text { Ringer Laktat }\end{array}$ & 2 hari \\
\hline 6. & $\mathrm{P}$ & 51 & $\begin{array}{l}\text { Pantoprazol } \\
\text { Ondancetron } \\
\text { Rebamipide } \\
\text { Inpepsa } \\
\mathrm{NaCl} \text { Infus }\end{array}$ & 3 hari \\
\hline 7. & $\mathrm{P}$ & 43 & $\begin{array}{l}\text { Pantoprazol } \\
\text { Ondancetron } \\
\text { Fentanyl } \\
\text { Inpepsa } \\
\text { Futrolit Infus }\end{array}$ & 5 hari \\
\hline 8. & $\mathrm{P}$ & 57 & $\begin{array}{c}\text { Pantoprazol } \\
\text { Rebimipide } \\
\text { Omeprazol } \\
\text { Inpepsa } \\
\text { Metoklopramid } \\
\text { Ringer Laktat Infus }\end{array}$ & 10 hari \\
\hline 9. & $\mathrm{P}$ & 90 & $\begin{array}{c}\text { Pantoprazole } \\
\text { Inpepsa } \\
\text { Lansoprazol } \\
\text { Ringer Laktat Infus }\end{array}$ & 4 hari \\
\hline 10. & $\mathrm{P}$ & 30 & $\begin{array}{c}\text { Pantoprazol } \\
\text { Na Metamizole } \\
\text { Rebimipide } \\
\text { Metoklopramid } \\
\text { Ringer Laktat Infus }\end{array}$ & 2 hari \\
\hline
\end{tabular}




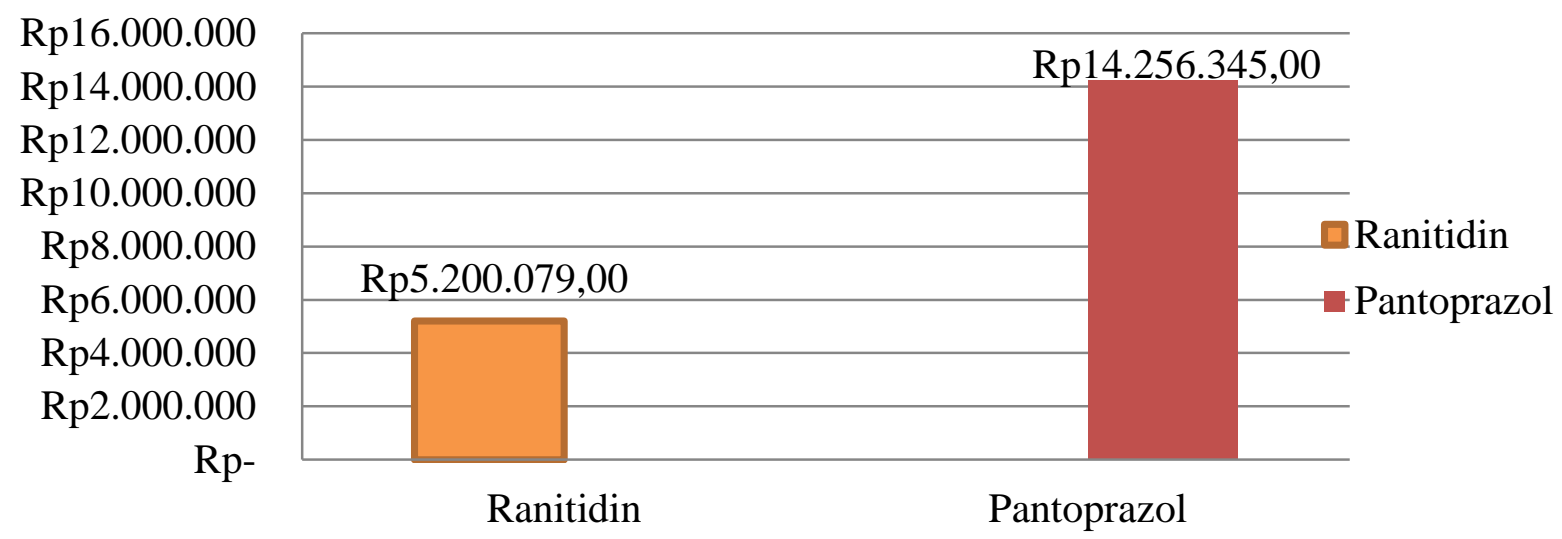

Gambar 3. Diagram Biaya Obat Gastritis yang paling minimal yang dikeluarkan pasien di RSUD Abdul Wahab Sjahranie Samarinda.

\section{Analisis Biaya}

Analisis yang digunakan untuk menentukan obat yang memiliki biaya yang paling minimal yang dikeluarkan pasien yaitu dengan metode CMA (Cost Minimization Analysis), dimana jumlah total biaya medik yang dikeluarkan oleh pasien dibagi dengan jumlah kasus yang terjadi tiap-tiap terapi.

Dari Gambar 3, dihitung rata-rata per pasien yang diperoleh dari penjumlahan biaya pengobatan, biaya perawatan/biaya kamar serta biaya tindakan kemudian dibagi jumlah kasus sehingga diperoleh rata-rata biaya medik per pasien sebesar Rp.5.200.079,- yang menggunakan ranitidin sedangkan ratarata biaya medik per pasien pada pantoprazol sebesar Rp.14.256.345,-Dilihat dari hasil yang didapat biaya yang dikeluarkan pasien yang menggunakan ranitidin lebih kecil dibandingkan dengan pasien yang menggunakan pantoprazol. Diketahui obat ranitidin lebih murah dibandingkan pantoprazol dengan harga adalah $\mathrm{Rp}$ 95.000,-/ampul dan pantoprazol sendiri adalah $\mathrm{Rp}$ 137.300,/vial. Hal ini dikarenakan penggunaan ranitidin secara single dose dan pantoprazole secara multipledose.

\section{KESIMPULAN}

Berdasarkan penelitian yang telah dilakukan dapat disimpulkan bahwa pasien gastritis yang diambil terdapat 15 pasien dengan jumlah laki-laki sebanyak 2 pasien, sedangkan perempuan sebanyak 13 pasien. Obat gastritis yang paling sering digunakan di RSUD Abdul Wahab Sjahranie Samarinda adalah Ranitidin dan Pantoprazol. Obat gastritis yang memiliki biaya paling minimal yang dianalisis dengan metode CMA adalah ranitidin.

\section{DAFTAR PUSTAKA}

[1] Muttaqin, Arif \& Kumala Sari. 2011. Gangguan Gastrointestinal: Aplikasi Asuhan Keperawatan Medikal bedah. Jakarta: Salemba Medika.

[2] Laumba, Febrianti. 2017. Analisis Efektivitas Biaya Pada Pasien Gastritis Kronik Rawat Inap di RSU Pancaran Kasih GMIM Manado. Jurnal Ilmiah Farmasi - UNSRAT Vol. 6 No. 3

[3] Abdullah. 2008. Ilmu Penyakit Dalam (internal medical disease). Universitas Sumatera Utara: Medan

[4] Gani. 1999. Teori Biaya Buku Panduan Analisis Biaya Dan Penyesuaian Tarif Pelayanan Kesehatan Di Indonesia. FKM UI: Jakarta 
Analisis Minimalisasi Biaya (Cost-Minimization Analysis) Pasien Gastritis Rawat Inap di RSUD Abdul Wahab Sjahranie Samarinda

[5] Margareth, S. 2014. The Reletionship Between Eating Habits With The Gastritis At The Medical Faculty Level Of Student 2010 Sam Ratulangi University Manado. Jurnal. Universitas Sam Ratulangi.
[6] Salamanya, Arfenilla. 2014. Kajian Penggunaan Obat Gatritis Pasien Rawat Inap Di RSUD Toto Kabila Kabupaten Bone Bolango. FIKK Universitas Negeri Gorontalo: Gorontalo

[7] Tjay, Toan Hoan \& Rahardja, Kirana. 2007. Obat-Obat Penting. Edisi ke enam. Elex Media Komputindo. Jakarta. 